\title{
Effect of Co and Ni substitution on the two magnetostructural phase transitions in $\mathrm{Fe}_{1.12} \mathrm{Te}$
}

\author{
Cevriye Koz, ${ }^{1, *}$ Sahana Rößler, ${ }^{1}$ Alexander A. Tsirlin, ${ }^{1,2,3}$ Ceren Zor, ${ }^{1,4}$ Gerçek Armağan, ${ }^{1,4}$ \\ Steffen Wirth, ${ }^{1}$ and Ulrich Schwarz ${ }^{1, \dagger}$ \\ ${ }^{1}$ Max Planck Institute for Chemical Physics of Solids, Nöthnitzer Straße 40, 01187 Dresden, Germany \\ ${ }^{2}$ National Institute of Chemical Physics and Biophysics, 12618 Tallinn, Estonia \\ ${ }^{3}$ Experimental Physics VI, Center for Electronic Correlations and Magnetism, Institute of Physics, University of Augsburg, \\ 86135 Augsburg, Germany \\ ${ }^{4}$ Koç University Chemistry Department, Rumelifeneri Yolu 34450 Sariyer Istanbul, Turkey
}

(Received 3 September 2015; published 6 January 2016)

\begin{abstract}
Here we present the results of high-resolution x-ray diffraction experiments along with specific heat, resistivity, and magnetization measurements of chemically well-characterized $\mathrm{Fe}_{1.12-x} M_{x} \mathrm{Te}(M=\mathrm{Co}$, Ni) samples. The motivation is to investigate how the two coupled magnetostructural phase transitions in the antiferromagnetic parent compound $\mathrm{Fe}_{1.12} \mathrm{Te}$ of chalcogenide superconductors can be tuned. While the two-step magnetostructural transition (tetragonal-to-orthorhombic followed by orthorhombic-to-monoclinic) persists in $\mathrm{Fe}_{1.10} \mathrm{Co}_{0.02} \mathrm{Te}$, only one, tetragonal-to-orthorhombic transition was observed in $\mathrm{Fe}_{1.10} \mathrm{Ni}_{0.02} \mathrm{Te}$. Upon increasing the Co and $\mathrm{Ni}$ substitution, the structural phase transitions and the long-range magnetic order are systematically suppressed without any sign of superconductivity. For high substitution levels $(x \geqslant 0.05)$, a spin-glass-like behavior was observed and the low-temperature structure remains tetragonal. From our results, it can be inferred that the electron doping strongly suppresses the magnetostructural phase transitions.
\end{abstract}

DOI: 10.1103/PhysRevB.93.024504

\section{INTRODUCTION}

Iron chalcogenides, $\mathrm{Fe}_{1+y}(\mathrm{Se}, \mathrm{Te})$, have attracted much attention because of their simple crystal structure among the Fe-based superconductors. The crystal structure of the parent compounds, $\mathrm{Fe}_{1+y} \mathrm{Se}$ and $\mathrm{Fe}_{1+y} \mathrm{Te}$, belongs to the tetragonal $P 4 / \mathrm{nmm}$ space group and comprises basic building blocks of edge-sharing $\mathrm{Fe}(\mathrm{Se}, \mathrm{Te})_{4}$ tetrahedra, which form layers orthogonal to the $c$ axis. The chemical composition of single-phase superconducting $\mathrm{Fe}_{1+y} \mathrm{Se}$ is very close to $1: 1$ $[1,2]$. In contrast, the isotypic phase of the heavier homologue tellurium, $\mathrm{Fe}_{1+y} \mathrm{Te}$, occurs only in the presence of excess $\mathrm{Fe}$ $(0.06 \leqslant y \leqslant 0.15)$ [3], which is considered to be situated in the interstitial $2 c$ crystallographic sites within the tellurium planes [4].

$\mathrm{Fe}_{1+y} \mathrm{Te}$ exhibits a rich phase diagram with respect to tuning parameters like temperature [3-11], pressure [1215], or chemical substitution [16,17]. Similar to the parent compounds of $\mathrm{Fe}$-pnictides, $\mathrm{Fe}_{1+y} \mathrm{Te}$ is antiferromagnetic. However, contrary to the former, experimental evidences suggest that the antiferromagnetism of $\mathrm{Fe}_{1+y} \mathrm{Te}$ can not be described by the nesting properties of the Fermi surface. This is because the vector connecting the hole and electron pockets in the Brillouin zone [18] does not match with the antiferromagnetic propagation vector determined by neutron scattering experiments [4]. Further, a large ordered moment of about $2 \mu_{\mathrm{B}} / \mathrm{Fe}$ detected in the antiferromagnetic phase $[16,17]$ as well as a Curie-Weiss behavior observed [19] in the magnetic susceptibility above the ordering temperature suggest a scenario of local magnetic moments.

It has been observed early on that the magnetic and structural properties of $\mathrm{Fe}_{1+y} \mathrm{Te}$ display strong dependencies

\footnotetext{
*koz@cpfs.mpg.de

†schwarz@cpfs.mpg.de
}

on the amount of excess Fe, $y[3,4,6,8,9]$. A density functional calculation has predicted a large local moment of $2.4 \mu_{\mathrm{B}} / \mathrm{Fe}$ for the excess $\mathrm{Fe}$, with each excess $\mathrm{Fe}$ donating one carrier to the system [20]. The interaction of the excess Fe with the $\mathrm{FeTe}$ layer has been observed in the $\mathrm{x}$-ray diffuse scattering experiments [21]. Further, excess $\mathrm{Fe}$ in $\mathrm{Fe}_{1+y} \mathrm{Te}_{1-x} \mathrm{Se}_{x}$ has been found to be essential for magnetism, but proved to be detrimental for superconductivity [22]. Note that about $10 \%$ substitution of Se for Te induces superconductivity [23-25]. Therefore the following questions naturally arise: (i) in which way are the interactions altered if the $\mathrm{Fe}$ is partially replaced by other transition metal ions? (ii) What is the influence of doping on the physical properties? (iii) Can superconductivity be induced in $\mathrm{Fe}_{1+y} \mathrm{Te}$ by substituting other transition metal ions for $\mathrm{Fe}$ ? To address these questions, here, we investigated the effect of $\mathrm{Co}$ and $\mathrm{Ni}$ substitution for $\mathrm{Fe}$ in $\mathrm{Fe}_{1.12} \mathrm{Te}$. These substitutions typically lead to more electron doping into the system. The excess $\mathrm{Fe}$ content of $\mathrm{Fe}_{1.12} \mathrm{Te}$ falls in the intermediate composition range $0.11<y \leqslant 0.13$, for which the compounds display two magnetostructural phase transitions $[3,6,8]$. In the specific case of $y=0.12$, a continuous transition at $57 \mathrm{~K}$ and a first-order phase transition at $46 \mathrm{~K}$ were observed [3]. Our results indicate that, although the magnetostructural phase transitions can be systematically suppressed by Co and Ni substitution, superconductivity does not appear down to $2 \mathrm{~K}$ and for up to $15 \%$ replacement of Fe.

\section{EXPERIMENTAL}

Polycrystalline samples, $\mathrm{Fe}_{1.12-x} M_{x} \mathrm{Te}(M=\mathrm{Co}$, Ni and $x=0.00,0.02,0.05,0.10$, and 0.15 ) were synthesized by utilizing solid-state reactions of the elements, Fe (Alfa Aesar, 99.995\%), Te pieces (Chempur, 99.9999\%), and Ni (Alfa Aesar, 99.996\%), or Co (Alfa Aesar, 99.999\%) powders. The procedure for the synthesis of these materials was similar to those used for pure $\mathrm{Fe}_{1+y} \mathrm{Te}$ [13]. The samples were characterized 
by powder x-ray diffraction (PXRD) using Co $\mathrm{K}_{\alpha 1}$ radiation $(\lambda=1.788965 \AA)$. The lattice parameters of the samples were calculated with $\mathrm{LaB}_{6}$ as an internal standard in the $\mathrm{x}$-ray powder diffraction experiments. The chemical compositions of the synthesized samples were determined by energy dispersive $\mathrm{X}$-ray (EDX) analysis and the inductively coupled plasma (ICP) method. The specific heat $C_{p}(T)$ and the resistivity $\rho(T)$ were measured using a Quantum Design physical property measurement system (PPMS). The dc-magnetic susceptibility $\chi(T)$ was obtained by means of a superconducting quantum interference device (SQUID) magnetometer. For synchroton $\mathrm{X}$-ray diffraction measurements, samples were ground and sieved (particle size $\leqslant 20$ micron). Following that, the powders were sealed in quartz ampoules under vacuum $\left(10^{-5}\right.$ bar $)$ and annealed at $673 \mathrm{~K}$ for 2 days in order to homogenize the cast reaction product. This procedure improved the sample crystallinity and reduced the peak-width in PXRD by about a factor 2. Temperature-dependent $\mathrm{X}$-ray powder diffraction data were collected on the high-resolution beamline ID22 $(\lambda=0.40067 \AA)$ at the ESRF, Grenoble, using a special He-flow cryostat adapted to the diffraction setup environment. Lattice parameter determination and structure refinements were performed by the Rietveld method using JANA2006 [26]. In the Rietveld refinement procedures, anisotropic strain broadening and the March-Dollase approach for describing the preferred orientation were applied [27,28].

\section{RESULTS AND DISCUSSION}

Room temperature PXRD patterns of $\mathrm{Fe}_{1.12-x} \mathrm{Ni}_{x} \mathrm{Te}$ $(0.00 \leqslant x \leqslant 0.15)$ are displayed in Fig. 1(a). All reflections can be indexed on the basis of a tetragonal unit cell in space group $P 4 / \mathrm{nmm}$. Cobalt substitution gives a similar result, except for $x=0.15$. In the PXRD pattern of $\mathrm{Fe}_{0.97} \mathrm{Co}_{0.15} \mathrm{Te}$, a small amount of impurity phase was detected. The diffraction lines indicate that the crystal structure of the minority component is related to the NiAs-type structure, and from the EDX analysis, the composition of this secondary phase was determined to be $\mathrm{Fe}_{0.47} \mathrm{Co}_{0.20} \mathrm{Te}$. Therefore this sample was not used for further investigations. The variations of lattice parameters for both $\mathrm{Co}$ and $\mathrm{Ni}$ substituted samples are given in Fig. 1(b). The lattice parameter $c$ decreases upon increasing substitution content for both transition metals. For the $a$ parameter, only the Co substitution induces a significant decrease. Overall, the unit cell volumes of Co and Ni substituted samples decrease with increasing substitution level, in agreement with earlier reported findings for $\mathrm{Fe}_{1.1-x} \mathrm{Ni}_{x} \mathrm{Te}$ [29] as well as with $\mathrm{Co}$ and Ni substituted $\mathrm{Fe}_{1+y} \mathrm{Se}$ and $\mathrm{Fe}_{1+y} \mathrm{Se}_{0.5} \mathrm{Te}_{0.5}$ [30-34]. Such a decrease of the volume is in accord with the smaller ionic radii of $\mathrm{Co}^{2+}(0.58 \AA)$ and $\mathrm{Ni}^{2+}(0.55 \AA)$ in comparison to that of $\mathrm{Fe}^{2+}(0.63 \AA)$ in tetrahedral coordination [35].

The compositions of the samples were carefully analyzed by the EDX and ICP methods. The back-scattered electron (BSE) images of all investigated samples (not shown), except for $\mathrm{Fe}_{0.97} \mathrm{Co}_{0.15} \mathrm{Te}$, confirm that they are single phase. This implies that both $\mathrm{Co}$ and $\mathrm{Ni}$ can effectively replace $\mathrm{Fe}$ within the investigated substitution ranges. The experimentally determined compositions in comparison to the starting ones are listed in Table I. They are in good agreement within experimental error except for the Co substituted sample with
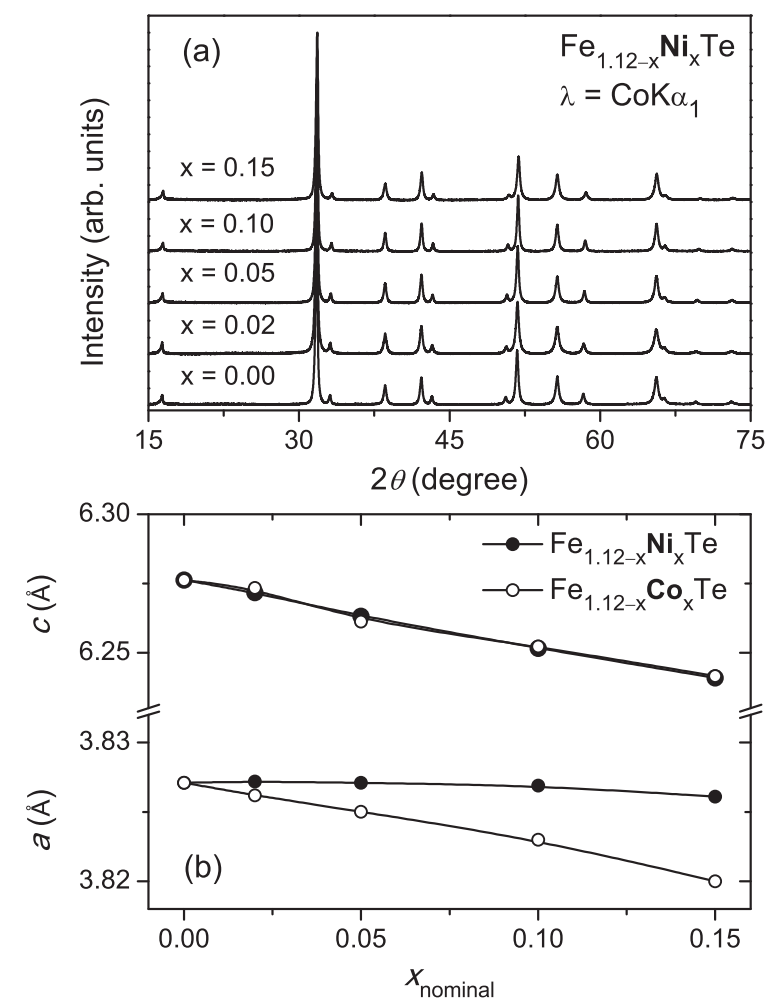

FIG. 1. (a) Powder x-ray diffraction diagram of samples with nominal composition $\mathrm{Fe}_{1.12-x} \mathrm{Ni}_{x} \mathrm{Te}$ for $x=0.00-0.15$ at room temperature. (b) Evolution of the lattice parameters upon increasing $\mathrm{Co}$ and $\mathrm{Ni}$ content. The error bars of the lattice parameters are smaller than the size of the symbols.

$x=0.02$. Note that the errors of the EDX results for the Co containing samples are larger than the values indicated in parenthesis (which assume a random distribution of the deviations) because of partial overlap of the $\mathrm{FeK}_{\beta 1}$ line with the $\mathrm{CoK}_{\alpha 1}$ line, i.e., they are systematic errors.

The temperature dependence of the specific heat $C_{p}(T)$ of $\mathrm{Fe}_{1.12-x} M_{x} \mathrm{Te}$ is presented in Figs. 2(a) and 2(b) for comparison. As mentioned before, in the parent compound $\left(\mathrm{Fe}_{1.12} \mathrm{Te}\right)$, two consecutive phase transitions have been reported [3,8-11]. With a tiny amount of substitution by $\mathrm{Ni}$ or $\mathrm{Co}$ for $\mathrm{Fe}$ $(x=0.02)$, however, only one prominent transition is visible in

TABLE I. Experimentally determined compositions of $\mathrm{Fe}_{1.12-x} M_{x} \mathrm{Te}(M=\mathrm{Co}, \mathrm{Ni})$ with energy dispersive X-ray (EDX) and chemical analysis by an inductively coupled plasma method (ICP). The nominal compositions of the substitutions are indicated by $x$. Standard deviations of determined composition are given in $1 \sigma$.

\begin{tabular}{lcc}
\hline \hline & $\begin{array}{c}\text { EDX } \\
\text { Composition }\end{array}$ & $\begin{array}{c}\mathrm{ICP} \\
\text { Composition }\end{array}$ \\
\hline 0.02 & $\mathrm{Fe}_{1.10(1)} \mathrm{Ni}_{0.02(1)} \mathrm{Te}_{0.99(1)}$ & $\mathrm{Fe}_{1.10(2)} \mathrm{Ni}_{0.02(1)} \mathrm{Te}_{1.01(2)}$ \\
0.05 & $\mathrm{Fe}_{1.07(1)} \mathrm{Ni}_{0.05(1)} \mathrm{Te}_{1.01(1)}$ & $\mathrm{Fe}_{1.07(1)} \mathrm{Ni}_{0.05(1)} \mathrm{Te}_{1.00(1)}$ \\
0.10 & $\mathrm{Fe}_{1.02(1)} \mathrm{Ni}_{0.10(1)} \mathrm{Te}_{1.00(1)}$ & $\mathrm{Fe}_{1.02(1)} \mathrm{Ni}_{0.10(1)} \mathrm{Te}_{1.00(1)}$ \\
0.15 & $\mathrm{Fe}_{0.97(1)} \mathrm{Ni}_{0.15(1)} \mathrm{Te}_{1.00(1)}$ & $\mathrm{Fe}_{0.97(1)} \mathrm{Ni}_{0.15(1)} \mathrm{Te}_{1.00(1)}$ \\
$0.02^{\mathrm{a}}$ & $\mathrm{Fe}_{1.08(2)} \mathrm{Co}_{0.04(1)} \mathrm{Te}_{0.97(1)}$ & $\mathrm{Fe}_{1.10(1)} \mathrm{Co}_{0.02(1)} \mathrm{Te}_{1.01(1)}$ \\
0.05 & $\mathrm{Fe}_{1.05(3)} \mathrm{Co}_{0.07(1)} \mathrm{Te}_{0.97(1)}$ & $\mathrm{Fe}_{1.06(2)} \mathrm{Co}_{0.06(2)} \mathrm{Te}_{1.00(2)}$ \\
0.10 & $\mathrm{Fe}_{1.01(2)} \mathrm{Co}_{0.11(1)} \mathrm{Te}_{0.98(1)}$ & $\mathrm{Fe}_{1.02(1)} \mathrm{Co}_{0.10(1)} \mathrm{Te}_{0.98(1)}$ \\
\hline \hline
\end{tabular}

${ }^{\mathrm{a}}$ See text. 


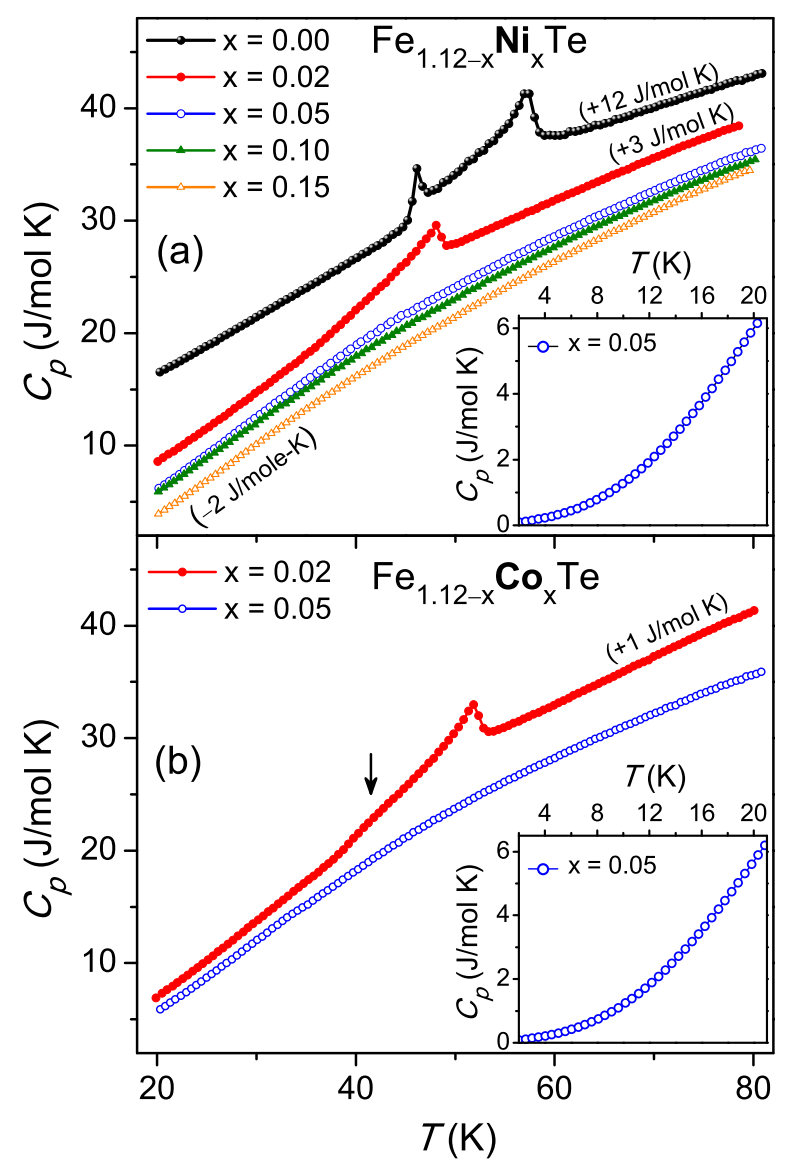

FIG. 2. Specific heat of (a) $\mathrm{Fe}_{1.12-x} \mathrm{Ni}_{x} \mathrm{Te}(x=0.00-0.15)$ and (b) $\mathrm{Fe}_{1.12-x} \mathrm{Co}_{x} \mathrm{Te}(x=0.02-0.05)$. The $C_{p}(T)$ data of some samples are shifted by the amounts given for each curve for clarity. The insets show specific heat of samples with $x=0.05$ below $20 \mathrm{~K}$. Arrow indicates the second transition temperature around $42 \mathrm{~K}$ in (b).

$C_{p}(T)$. The shape of this peak is $\lambda$-like, indicating a continuous nature of the phase transition. Therefore it can be inferred that the temperature of the continuous phase transition of $\mathrm{Fe}_{1.12} \mathrm{Te}$ decreases from $52 \mathrm{~K}(48 \mathrm{~K})$ for $2 \%$ Co $(\mathrm{Ni})$ substitution, respectively. Notice that, for Co substituted sample, a small hump around $42 \mathrm{~K}$ is visible. In the case of $\mathrm{Ni}$ substitution, the hump is even less pronounced. This behavior of $C_{p}(T)$ signals a second phase transition as in the case of $\mathrm{Fe}_{1.12} \mathrm{Te}$. Upon further increasing the substitution content $(x \geqslant 0.05)$, no peaks are visible in $C_{p}(T)$. The insets display $C_{p}(T)$ below $20 \mathrm{~K}$ for $\mathrm{Fe}_{1.12-x} M_{0.05} \mathrm{Te}$ samples indicating that even at lower temperatures no transition is observed in the specific heat measurements. The two representative samples with $x=0.05$ were measured down to $2 \mathrm{~K}$, with no indication for any additional transition in the low-temperature regime (insets to Fig. 2). Such transitions were also not expected for the other samples with $x>0.05$ and hence, they were only measured down to $20 \mathrm{~K}$.

The dc magnetic susceptibilities, $\chi(T)$, of $\mathrm{Fe}_{1.12-x} \mathrm{Ni}_{x} \mathrm{Te}$ $(x=0.02-0.15)$ and $\mathrm{Fe}_{1.12-x} \mathrm{Co}_{x} \mathrm{Te}(x=0.02-0.05)$ measured in a field of $0.1 \mathrm{~T}$ are presented in Fig. 3. The $\chi(T)$ of the samples with low $\mathrm{Ni}$ and Co substitution $(x=0.02)$ displays a transition into an antiferromagnetic state at $T_{N}$. For
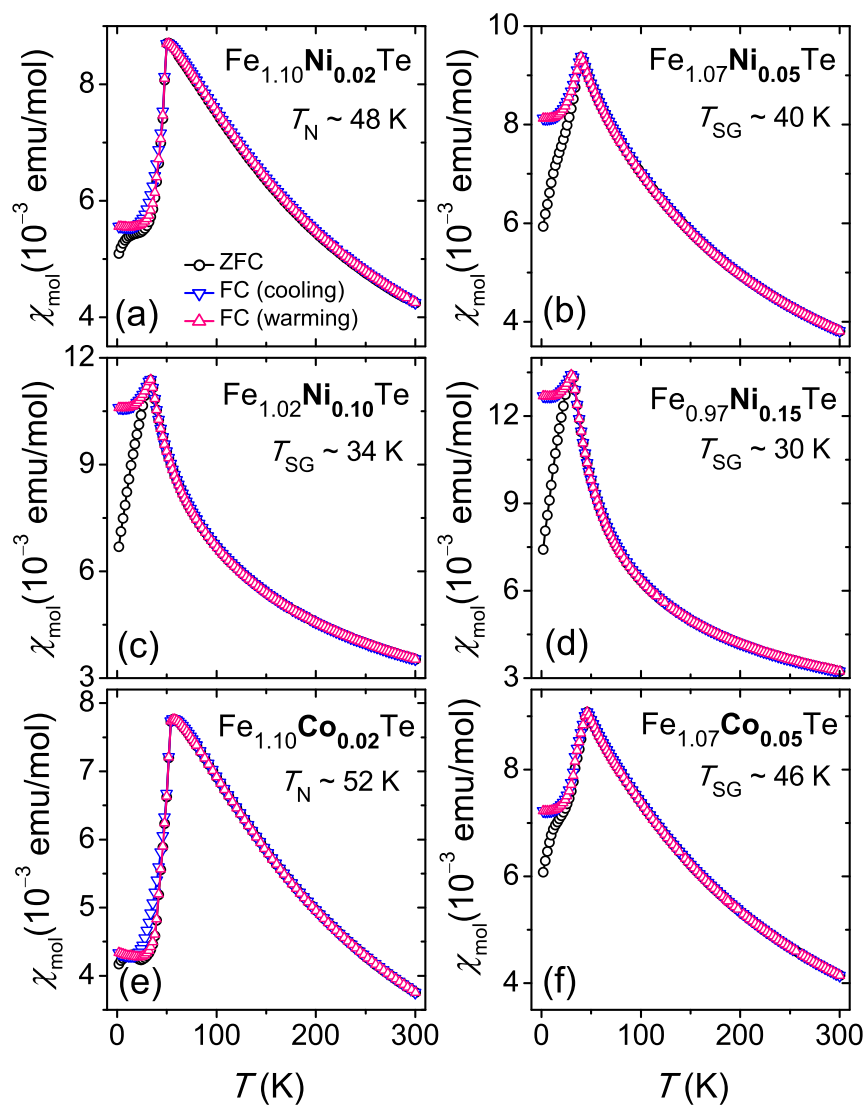

FIG. 3. Magnetic susceptibility of $\mathrm{Fe}_{1.12-x} \mathrm{Ni}_{x} \mathrm{Te}$ for $x=$ 0.02-0.15 (a)-(d) and $\mathrm{Fe}_{1.12-x} \mathrm{Co}_{x} \mathrm{Te}$ for $x=0.02,0.05$ (e)-(f) measured in a field of $0.1 \mathrm{~T}$. $T_{\mathrm{SG}}$ represent the onset of spin-glass-like behavior. Note that the legends in panel (a) are applicable to all other panels.

the smallest amount of nickel substitution, a second transition is indicated by a slope change around $20 \mathrm{~K}$. The temperatures of the transitions into the antiferromagnetic phase observed in the $\chi(T)$ measurements are consistent with those found in the $C_{p}(T)$ measurements. The $\chi(T)$ measured in zero-field cooled (ZFC) and field-cooled (FC) procedures display a bifurcation, which becomes more pronounced with increasing $\mathrm{Ni}$ substitution. Further, the temperature of this ZFC-FC irreversibility decreases from 48 to $30 \mathrm{~K}$ [Figs. 3(a)-3(d)] with increasing Ni substitution. This behavior is similar to the spin-glass-like behavior found in previous studies of $\mathrm{Cu}$ and $\mathrm{Ni}$ substituted $\mathrm{Fe}_{1+y} \mathrm{Te}[29,36]$. For equal amounts of $\mathrm{Ni}$ and Co substitution ( $x=0.02$ and 0.05$)$, the decrease in the spin-glass transition temperature as well as the width of the bifurcation in $\chi(T)$ for ZFC and FC measurements are less pronounced for Co substituted samples [Figs. 3(e)-3(f)]. In Fig. 4(a), $\chi(T)$ measurements for $\mathrm{Fe}_{1.02} \mathrm{Ni}_{0.10}$ Te performed in magnetic fields of $0.1,2$, and $4 \mathrm{~T}$ are presented. In the same figure, $1 / \chi(T)$ of the data taken at $4 \mathrm{~T}$ is also plotted. Above the transition temperature, the data measured in different magnetic fields overlap on each other. Similar behavior is also found in all measured $\mathrm{Fe}_{1.12-x} M_{x} \mathrm{Te}$ samples. The field-independent $\chi(T)$ confirms that the samples are free of ferromagnetic impurities. A similar conclusion was also drawn from the isothermal magnetization $M(H)$ [Fig. 4(b)] measurements at 


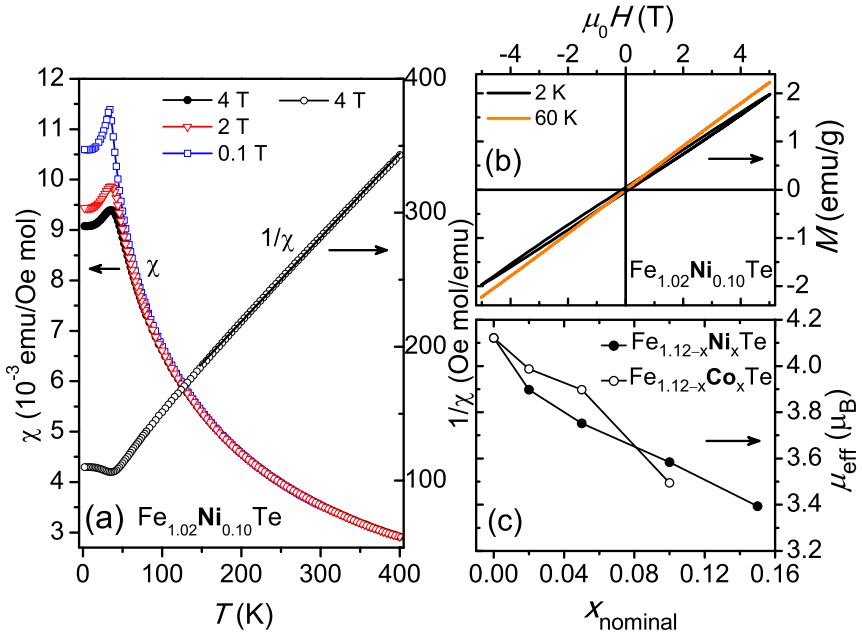

FIG. 4. (a) The dc-magnetic susceptibility (field-cooled protocol, $\mu_{0} H=0.1,2$, and $4 \mathrm{~T}$ ) and the inverse magnetic susceptibility $\left(\mu_{0} H=4 \mathrm{~T}\right)$ vs temperature of $\mathrm{Fe}_{1.02} \mathrm{Ni}_{0.10} \mathrm{Te}$. The gray line represents the linear fit to $1 / \chi$ vs $T$ in the range $150 \mathrm{~K} \leqslant T \leqslant 400 \mathrm{~K}$. (b) Isothermal magnetization curves of $\mathrm{Fe}_{1.02} \mathrm{Ni}_{0.10} \mathrm{Te}$ at $2 \mathrm{~K}$ and 60 $\mathrm{K}$. (c) Effective magnetic moment $\left(\mu_{\text {eff }}\right)$ of substituted samples as estimated from fitting the Curie-Weiss law to the inverse magnetic susceptibility data for $\mathrm{Fe}_{1.12-x} M_{x} \mathrm{Te}(M=\mathrm{Co}$, Ni and $x=0-0.15)$ at $\mu_{0} H=4 \mathrm{~T}$. The error bars of $\mu_{\mathrm{eff}}$ are smaller than the size of the symbols.

2 and $60 \mathrm{~K}$. The linear behavior of $M(H)$ further confirms the absence of magnetic impurities. The $\chi(T)$ data in the temperature range $150-400 \mathrm{~K}$ measured in a field of $4 \mathrm{~T}$ were fitted with a Curie-Weiss law, $\chi=C /(T-\theta)$. The fittings yielded negative values for the Weiss constant $\theta$, suggesting the presence of antiferromagnetic correlations. The effective magnetic moment $\mu_{\mathrm{eff}}$ was calculated from the Curie constant using $C=N \mu_{\text {eff }}^{2} / 3 k_{B}$, where $N$ is the Avogadro number and $k_{B}$ the Boltzmann constant. In Fig. 4(c), the estimated $\mu_{\text {eff }}$ upon increasing substitution is plotted. The value of $\mu_{\text {eff }}$ decreases with increasing $x$. For $\mathrm{Fe}_{1.12} \mathrm{Te}, \mu_{\text {eff }}=4.1 \mu_{\mathrm{B}}$, which corresponds to the total spin $S \approx 3 / 2$, calculated using the spin-only formula, $\mu_{\text {eff }}=\sqrt{4 S(S+1)} \mu_{\mathrm{B}}$. The value of $S$ obtained here is consistent with that found in the neutron scattering experiments [37], but lower than $S=2$ expected for $\mathrm{Fe}^{2+}$ in the tetrahedral coordination. Furthermore, a reduction in $\mu_{\text {eff }}$ upon substitution is generally consistent with the reduced value of the local spin: $S=3 / 2\left(\mathrm{Co}^{2+}\right)$ and $S=1\left(\mathrm{Ni}^{2+}\right)$.

In Fig. 5, the temperature dependence of the normalized resistance $R(T) / R_{150 \mathrm{~K}}$ measured in the warming cycle for $\mathrm{Fe}_{1.12-x} M_{x} \mathrm{Te}(x=0.02-0.10)$ samples are plotted. For $x=$ 0.02 , the phase transitions at around 52 and $48 \mathrm{~K}$ can be clearly seen for both, Co and Ni substituted samples, respectively. For $x \geqslant 0.05, R(T)$ curves exhibit insulating behavior. Thus, from the resistivity, magnetic susceptibility, and specific heat measurements, it can be concluded that $\mathrm{Fe}_{1.10} M_{0.02}$ Te samples display a clear antiferromagnetic transition. In the samples with $x \geqslant 0.05$, a spin-glass insulating behavior appears to prevail.

In order to check whether these magnetic transitions involve a structural component as well, we performed low-temperature PXRD measurements. The high-resolution synchrotron PXRD of $\mathrm{Fe}_{1.12-x} M_{x} \mathrm{Te}$ samples were conducted between 10 to
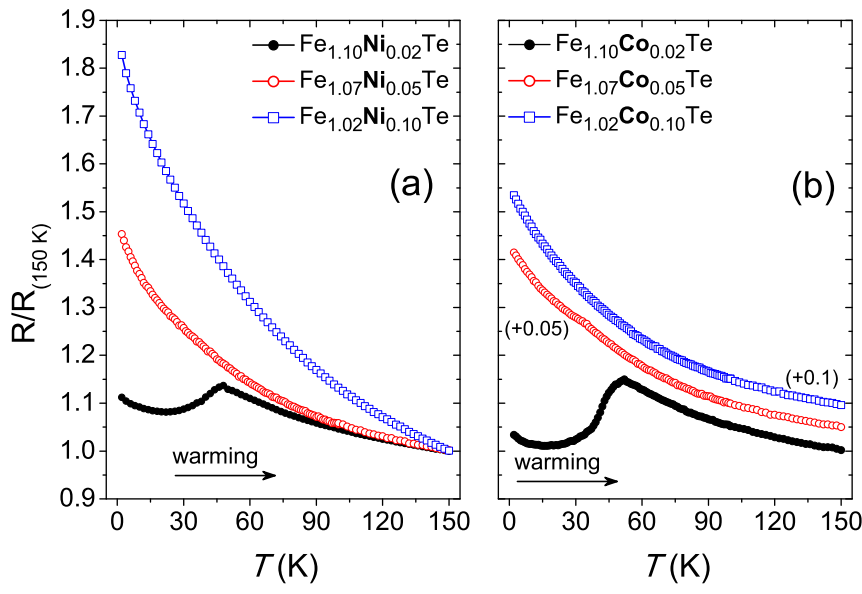

FIG. 5. Normalized resistance $R / R_{150 \mathrm{~K}}$ measured during the warming cycle of (a) $\mathrm{Fe}_{1.12-x} \mathrm{Ni}_{x} \mathrm{Te}$ and (b) $\mathrm{Fe}_{1.12-x} \mathrm{Co}_{x} \mathrm{Te}$ $(x=0.02-0.10)$. The normalized resistance $R / R_{150 \mathrm{~K}}$ data for $\mathrm{Fe}_{1.07} \mathrm{Co}_{0.05} \mathrm{Te}$ and $\mathrm{Fe}_{1.02} \mathrm{Co}_{0.10} \mathrm{Te}$ are shifted by the amounts given for each curve for clarity.

$100 \mathrm{~K}$. The details of the structure refinements are compiled in Tables II-III and Tables IV-VIII (see Appendix). Initially, we focus on the samples with the lowest amount $(x=0.02)$ of $\mathrm{Co}$ and $\mathrm{Ni}$ substitution. Figures 6(a) and 6(b) represent selected regions of the PXRD patterns for the (112) and (200) Bragg reflections of $\mathrm{Fe}_{1.10} \mathrm{Ni}_{0.02} \mathrm{Te}$ and $\mathrm{Fe}_{1.10} \mathrm{Co}_{0.02} \mathrm{Te}$. This part of the diffraction pattern is selected because a decrease to orthorhombic symmetry Pmmn involves a peak splitting of the tetragonal (200) reflection while a transition into the monoclinic $\left(P 2_{1} / m\right)$ phase, as it is characteristic for $\mathrm{Fe}_{1+y} \mathrm{Te}$ for $y \leqslant 0.11$ involves the separation of both the tetragonal

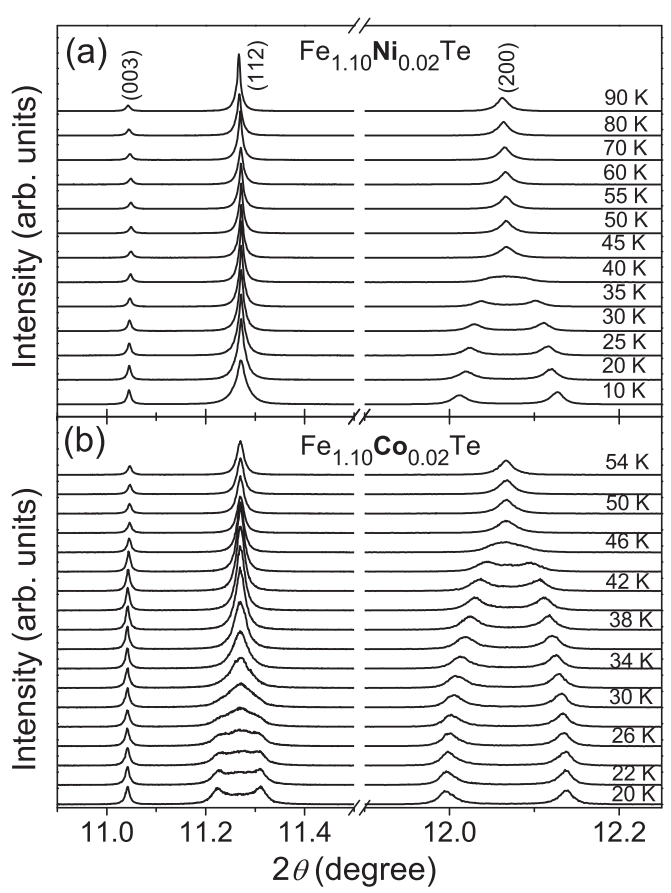

FIG. 6. Temperature dependence of PXRD patterns for (a) $\mathrm{Fe}_{1.10} \mathrm{Ni}_{0.02} \mathrm{Te}$ and (b) $\mathrm{Fe}_{1.10} \mathrm{Co}_{0.02} \mathrm{Te}$ during the cooling cycle. The measurements were performed in the cooling cycle. 


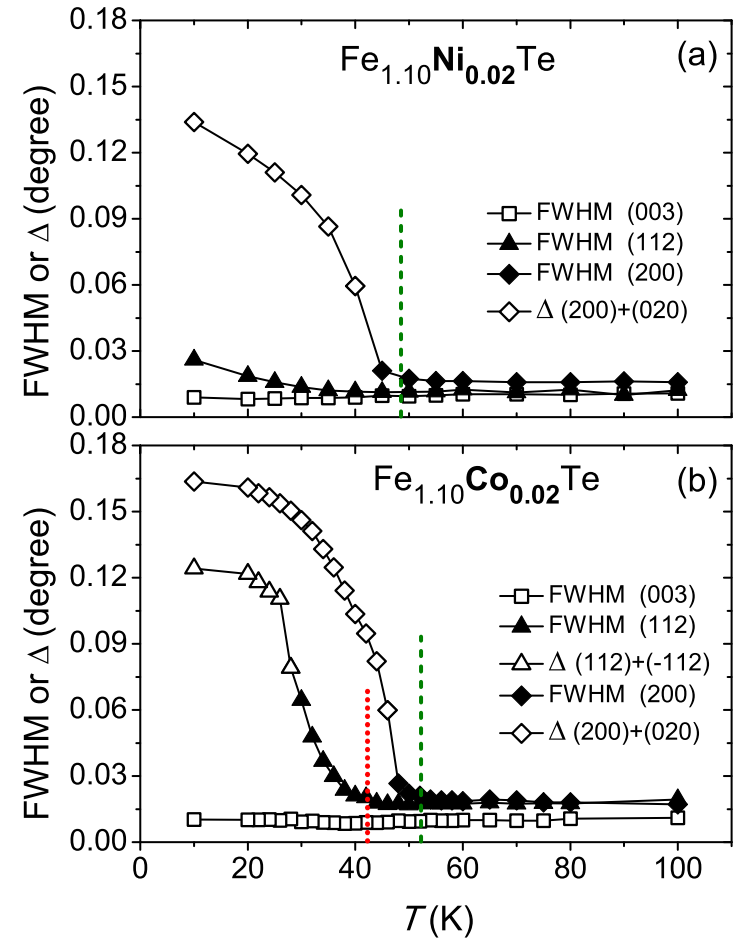

FIG. 7. Temperature evolution of FWHM or $\Delta$ values of (a) $\mathrm{Fe}_{1.10} \mathrm{Ni}_{0.02} \mathrm{Te}$ and (b) $\mathrm{Fe}_{1.10} \mathrm{Co}_{0.02} \mathrm{Te}$. Here, $\Delta$ is described as the sum of the peak FWHM plus the separation of the peak maxima in case of visible splitting, i.e., a value which increases significantly upon peak splitting. Dashed and dotted lines indicate the transition temperatures obtained from the specific heat.

(200) and (112) Bragg reflections. In the PXRD pattern of $\mathrm{Fe}_{1.10} \mathrm{Ni}_{0.02} \mathrm{Te}$, the visible change in the peak shape of the (200) reflection starts below $45 \mathrm{~K}$ and a clear separation into the (200) and the (020) reflections is observed at $35 \mathrm{~K}$. The onset temperature of this structural change is consistent with the magnetic transition into the antiferromagnetic phase. The broadening of the (112) reflection, which starts around 30 K [Fig. 6(a)], coincides with the second magnetic anomaly observed at low nickel contents. For the Co substituted sample, $\mathrm{Fe}_{1.10} \mathrm{Co}_{0.02} \mathrm{Te}$, the broadening of the (200) reflection is seen at $46 \mathrm{~K}$ and the peak splits into separated (200) and (020) reflections at $44 \mathrm{~K}$. The onset is slightly below the observed transition temperature of $52 \mathrm{~K}$ in specific heat. The broadening of the (112) reflection sets in just below $40 \mathrm{~K}$ and the splitting into the (112) and (-112) peaks becomes more pronounced at lower temperatures [Fig. 6(b)]. This change nicely coincides with the second (low temperature) anomaly observed in specific heat measurements at around $42 \mathrm{~K}$.

In Figs. 7(a) and 7(b), the full width at half maximum (FWHM) or $\Delta$ of selected reflections below $100 \mathrm{~K}$ for $\mathrm{Fe}_{1.12-x} M_{x} \mathrm{Te}$ are presented. Here, $\Delta$ is given [13] as the sum of the peak FWHM plus the separation of the peak maxima in case of a visible splitting. The (112) and (200) reflections were selected as those identifying the symmetry breaking, with (003) serving as a reference because its peak shape does not change across the structural transitions. For $\mathrm{Fe}_{1.10} \mathrm{Ni}_{0.02} \mathrm{Te}$ [Fig. 7(a)] broadening of the (200) reflection is taken as an indication that the transition into the antiferromagnetic phase
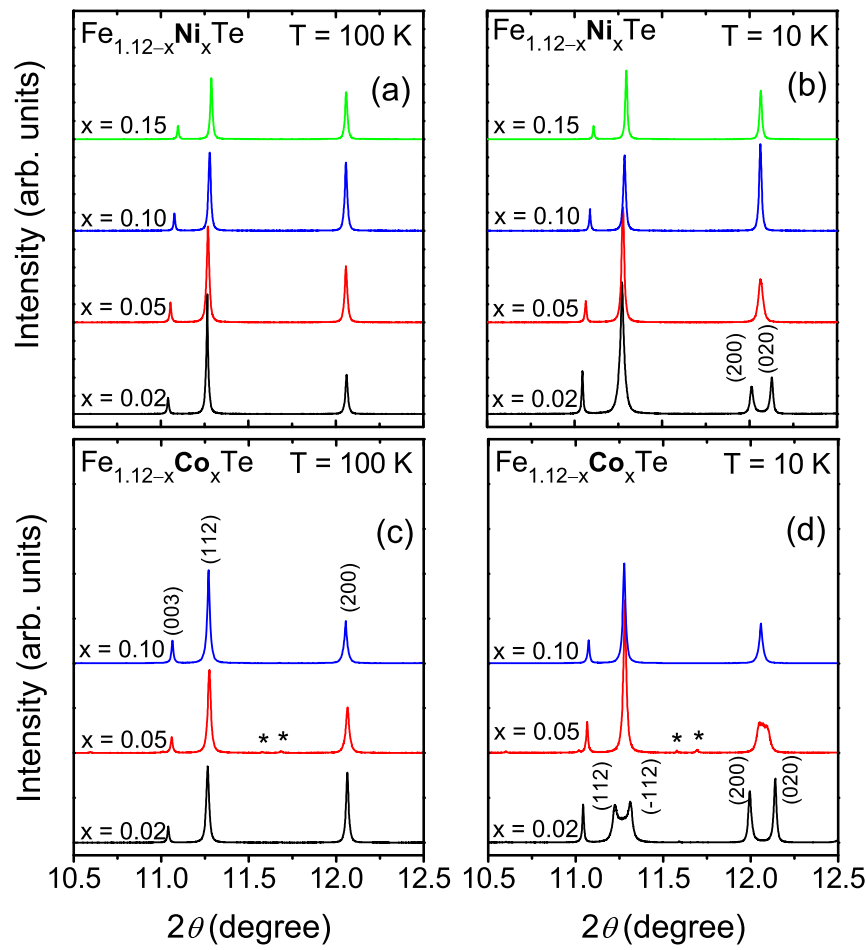

FIG. 8. Representative PXRD patterns of $\mathrm{Fe}_{1.12-x} \mathrm{Ni}_{x} \mathrm{Te}, x=$ $0.02-0.15$ at (a) $100 \mathrm{~K}$, (b) $10 \mathrm{~K}$ and $\mathrm{Fe}_{1.12-x} \mathrm{Co}_{x} \mathrm{Te}, x=0.02-0.10$ at (c) 100 and (d) $10 \mathrm{~K}$. Tiny peaks from trace amounts of unidentified impurity phases are indicated by asterisks on the PXRD pattern of $\mathrm{Fe}_{1.07} \mathrm{Co}_{0.05} \mathrm{Te}$.

is associated with a transition into orthorhombic symmetry. A subtle broadening of the (112) reflection below $30 \mathrm{~K}$ is taken as evidence for the second magnetic phase transition to coincide with the development of the monoclinic phase.

Figure 7(b) shows the temperature evolution of the FWHM values of selected reflections for $\mathrm{Fe}_{1.10} \mathrm{Co}_{0.02} \mathrm{Te}$. The magnitude of FWHM of the (200) reflection starts to increase below $48 \mathrm{~K}$, again, slightly below the temperature at which the anomaly in $C_{p}(T)$ is observed. The evolution of FWHM of $\mathrm{Fe}_{1.10} \mathrm{Co}_{0.02} \mathrm{Te}$ shows a similar behavior as in the case of $\mathrm{Fe}_{1.12} \mathrm{Te}$ [3], except that the phase transitions occur at slightly lower temperatures for the Co substituted sample. Rietveld refinements of these two samples were performed to obtain the relative phase fractions (in wt. \%) of the monoclinic and orthorhombic phases. According to these results, 5\%$10 \%$ of the $\mathrm{Fe}_{1.10} \mathrm{Ni}_{0.02} \mathrm{Te}$ sample adopts the monoclinic crystal structure at $10 \mathrm{~K}$, while the majority of the sample retains orthorhombic symmetry. The refined molar ratio of the orthorhombic to monoclinic phases in $\mathrm{Fe}_{1.10} \mathrm{Co}_{0.02} \mathrm{Te}$ at $10 \mathrm{~K}$ (i.e., articulately below the temperature of the transition in specific heat) amounts to $1: 2$, which is very similar to the ratio reported for $\mathrm{Fe}_{1.12} \mathrm{Te}$ [3]. Thus, for the same amount of $\mathrm{Co}$ and $\mathrm{Ni}$ substitution $(x=0.02)$, the tetragonal-to-orthorhombic transition shifts to much lower temperatures for Ni substituted samples than for the samples with Co substitution.

To compare the low-temperature behaviors of different compositions, the selected regions of PXRD patterns for the (112) and (200) Bragg reflections of $\mathrm{Fe}_{1.12-x} M_{x} \mathrm{Te}$ obtained at 100 and $10 \mathrm{~K}$ are given in Fig. 8. At $100 \mathrm{~K}$, well above the 


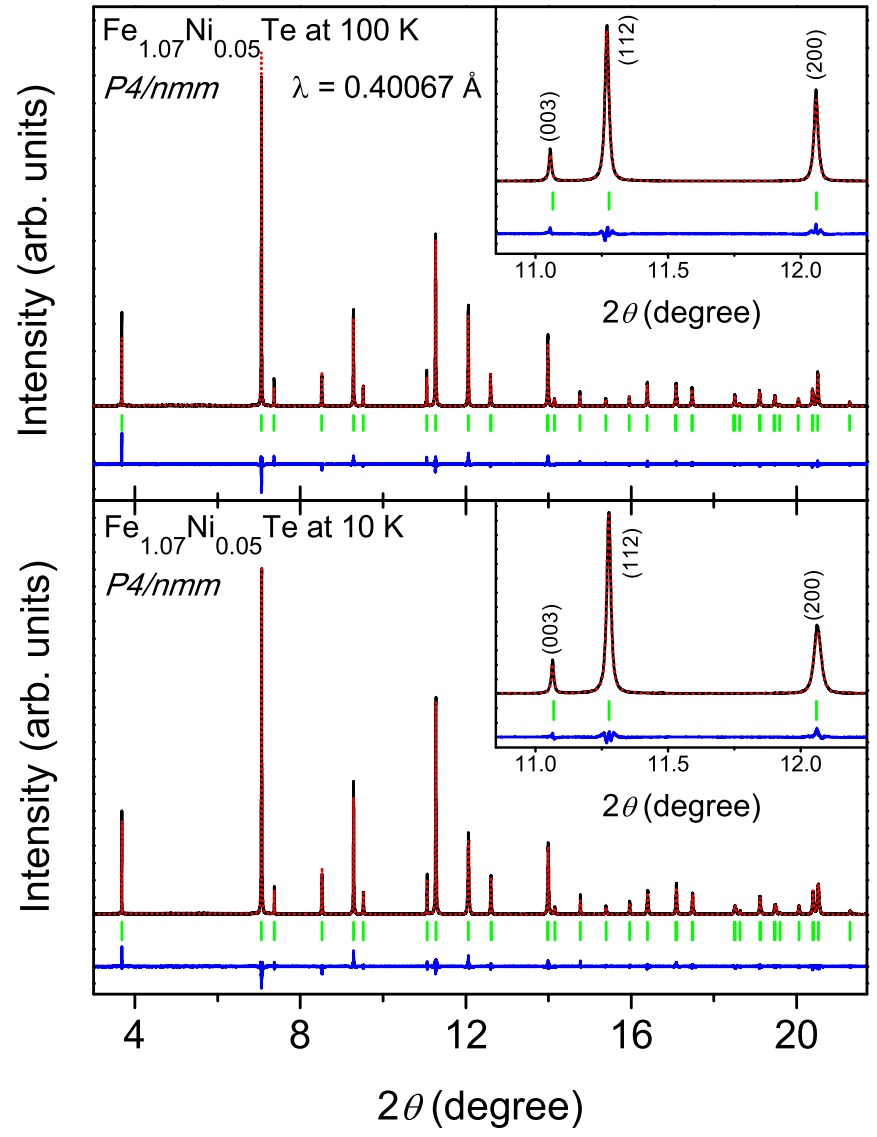

FIG. 9. Refined synchrotron powder x-ray diffraction patterns of $\mathrm{Fe}_{1.07} \mathrm{Ni}_{0.05} \mathrm{Te}$ at 100 and $10 \mathrm{~K}$.

temperature at which the phase transitions occur, all patterns can be indexed on the basis of a tetragonal cell in the space group $P 4 / \mathrm{nmm}$ [Figs. 8(a) and 8(c)]. Trace amounts of unidentified impurity peaks are observed in the PXRD pattern of $\mathrm{Fe}_{1.07} \mathrm{Co}_{0.05} \mathrm{Te}$ both above and below the phase transition temperature [Figs. 8(c)-8(d)]. As mentioned above, at $10 \mathrm{~K}$, the $\mathrm{Fe}_{1.10} \mathrm{Ni}_{0.02} \mathrm{Te}$ sample mainly adopts an orthorhombic structure. Upon increasing the amount of Ni to $x \geqslant 0.05$, peak splitting is observed neither for the (112) nor for the (200) reflections at $10 \mathrm{~K}$ (Fig. 8(b)), i.e., for these compositions $\mathrm{Fe}_{1.12-x} \mathrm{Ni}_{x} \mathrm{Te}$ retains the tetragonal lattice $(P 4 / \mathrm{nmm})$ down to $10 \mathrm{~K}$. Figure $8(\mathrm{~d})$ displays the representative PXRD pattern of the Co substituted samples at $10 \mathrm{~K}$. As mentioned above, $\mathrm{Fe}_{1.10} \mathrm{Co}_{0.02} \mathrm{Te}$ is a mixture of monoclinic and orthorhombic phases at $10 \mathrm{~K}$. A further increase in the Co substitution $(x=0.05)$ in $\mathrm{Fe}_{1.12-x} \mathrm{Co}_{x} \mathrm{Te}$ suppresses the splitting of the (112) reflection, and the (200) peak shape indicates that the sample is composed of a mixture of orthorhombic and tetragonal phases. In the case of $\mathrm{Fe}_{1.02} \mathrm{Co}_{0.10} \mathrm{Te}$, the pattern is compatible with tetragonal symmetry indicating that the low-temperature structural phase transitions are completely suppressed. These results once again suggest that the amount of Co substitution required for a certain shift of the transition temperature and finally suppressing the phase transitions is higher than in the case of Ni substitution. A similar situation

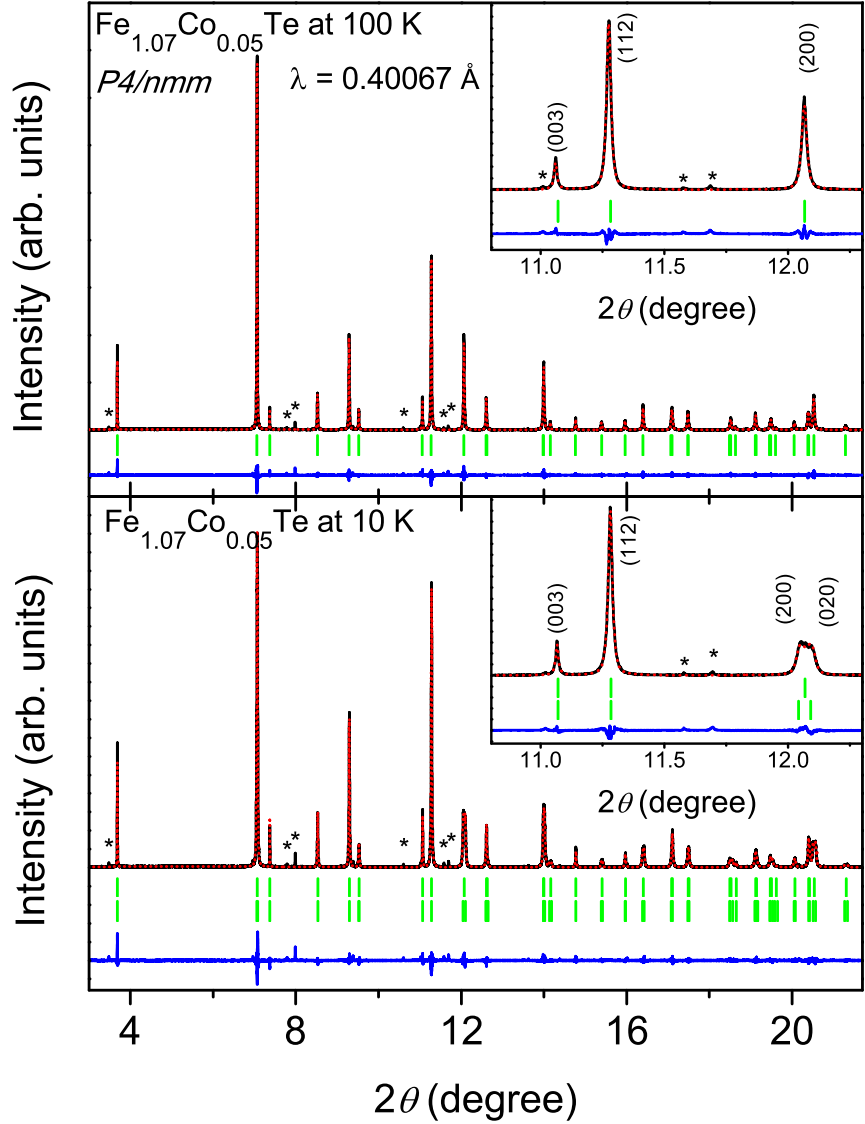

FIG. 10. Refined synchrotron powder x-ray diffraction patterns of $\mathrm{Fe}_{1.07} \mathrm{Co}_{0.05} \mathrm{Te}$ at $100 \mathrm{~K}$ and $10 \mathrm{~K}$. At $10 \mathrm{~K}$, the upper and lower Bragg reflections represent tetragonal and orthorhombic structures, respectively. An unidentified impurity phase is observed after annealing.

has been observed for the suppression of the superconductivity in substituted $\mathrm{Fe}_{1+y} \mathrm{Se}_{0.5} \mathrm{Te}_{0.5}$ samples: in the case of $5 \%$ Co substitution, the superconductivity is partly suppressed, while for the same amount of $\mathrm{Ni}$ substitution it is eliminated completely [38,39].

Rietveld refinement of PXRD patterns of $\mathrm{Fe}_{1.07} M_{0.05} \mathrm{Te}$ measured at 100 and $10 \mathrm{~K}$ are presented in Figs. 9 and 10 . At both temperatures, the XRD patterns of $\mathrm{Fe}_{1.07} \mathrm{Ni}_{0.05} \mathrm{Te}$ can be refined assuming a pure tetragonal phase. In order to reduce the number of free variables in the refinements, cobalt and nickel, respectively, are placed on the interstitial site in the refined structure model. However, x-ray powder diffraction data do not allow for a reliable distinction between iron, cobalt, or nickel atoms because of a similar total number of electrons and, thus, similar x-ray scattering power. Yet, the exact position of the transition metal atoms is not decisive for the investigated magnetic ordering effects since all transition metal atoms adopt high-spin configuration in the studied samples. Therefore the refinements were performed under the assumption that the $\mathrm{Ni}$ and $\mathrm{Co}$ atoms are located on the interstitial site $(2 c)$. The refined parameters of crystal 
TABLE II. Crystallographic data based on refinements using PXRD diagrams of $\mathrm{Fe}_{1.07} \mathrm{Ni}_{0.05} \mathrm{Te}$ in the tetragonal phase at $100 \mathrm{~K}$ and $10 \mathrm{~K}$. Atomic displacement parameters $U_{\text {iso }}$ are given in $\left(10^{-2} \AA^{2}\right)$. Fe 1 and Te are assumed as fully occupied and the occupancy parameters of these atoms are fixed to 1 .

\begin{tabular}{|c|c|c|}
\hline Temperature & $100 \mathrm{~K}$ & $10 \mathrm{~K}$ \\
\hline Space group & $\mathrm{P} 4 / \mathrm{nmm}$ & $\mathrm{P} 4 / \mathrm{nmm}$ \\
\hline$a(\AA)$ & $3.81489(2)$ & $3.81291(3)$ \\
\hline$c(\AA)$ & $6.23942(4)$ & $6.23447(5)$ \\
\hline$\beta$ (deg.) & 90 & 90 \\
\hline$R_{I} / R_{P}$ & $0.028 / 0.105$ & $0.021 / 0.096$ \\
\hline Number of reflections & 81 & 81 \\
\hline $\begin{array}{l}\text { Refined parameters for } \\
\text { profile/crystal structure } \\
\text { Atomic parameters }\end{array}$ & $22 / 7$ & $22 / 7$ \\
\hline $\mathrm{Fe} 1$ & $2 a\left(\frac{3}{4}, \frac{1}{4}, 0\right)$ & $2 a\left(\frac{3}{4}, \frac{1}{4}, 0\right)$ \\
\hline \multirow[t]{4}{*}{$\mathrm{Fe} 2^{\mathrm{a}}$} & $\begin{array}{c}U_{\text {iso }}=0.40(4) \\
2 c\left(\frac{1}{4}, \frac{1}{4}, z\right)\end{array}$ & $\begin{array}{c}U_{\text {iso }}=0.22(3) \\
2 c\left(\frac{1}{4}, \frac{1}{4}, z\right)\end{array}$ \\
\hline & $z=0.736(7)$ & $z=0.739(4)$ \\
\hline & $U_{\text {iso }}=0.7(0)$ & $U_{\text {iso }}=0.4(0)$ \\
\hline & $O c c .=0.066(3)$ & $O c c .=0.066(0)$ \\
\hline \multirow[t]{4}{*}{$\mathrm{Ni}^{\mathrm{a}}$} & $2 c\left(\frac{1}{4}, \frac{1}{4}, z\right)$ & $2 c\left(\frac{1}{4}, \frac{1}{4}, z\right)$ \\
\hline & $z=0.709(9)$ & $z=0.702(6)$ \\
\hline & $U_{\text {iso }}=0.7(0)$ & $U_{\text {iso }}=0.4(0)$ \\
\hline & $O c c .=0.050(3)$ & $O c c .=0.050(0)$ \\
\hline \multirow[t]{3}{*}{$\mathrm{Te}$} & $2 c\left(\frac{1}{4}, \frac{1}{4}, z\right)$ & $2 c\left(\frac{1}{4}, \frac{1}{4}, z\right)$ \\
\hline & $z=0.2824(2)$ & $z=0.2825(1)$ \\
\hline & $U_{\text {iso }}=0.54(2)$ & $U_{\text {iso }}=0.33(2)$ \\
\hline
\end{tabular}

$\overline{\text { a Atomic displacement parameters, } U_{\text {iso }} \text {, and occupancies are intrinsi- }}$ cally correlated and, therefore, cannot be refined independently. The atomic displacement parameters of the interstitial atoms are fixed at $U_{\text {iso }}=0.007 \AA^{2}$ at $100 \mathrm{~K}$ and $U_{\text {iso }}=0.004 \AA^{2}$ at $10 \mathrm{~K}$. The occupancies of interstitial atoms were refined separately without restricting their sum at $100 \mathrm{~K}$, and same occupancies were used in the refinement of the $10-\mathrm{K}$ data.

structures of the $\mathrm{Fe}_{1.07} \mathrm{Ni}_{0.05} \mathrm{Te}$ sample are listed in Table II. For $\mathrm{Fe}_{1.07} \mathrm{Co}_{0.05} \mathrm{Te}$, however, the pattern at $10-\mathrm{K}$ displays a partial splitting of the (200) reflection. This suggests that at low temperatures $\mathrm{Fe}_{1.07} \mathrm{Co}_{0.05} \mathrm{Te}$ is a mixture of orthorhombic and tetragonal phases. The relative phase fractions obtained from the Rietveld refinement are (in wt. \%) 55(1)\% and 45(1)\% for the tetragonal and orthorhombic phases, respectively. The details of the refinement of $\mathrm{Fe}_{1.07} \mathrm{Co}_{0.05} \mathrm{Te}$ are compiled in Table III. The small reflections indicated by asterisks in the PXRD patterns have not been observed in the as-grown sample. They only appeared after the annealing process. We have repeatedly performed careful phase searches using the ICSD [40] as well as the PDF4 database provided by ICDD (edition 2014). Unfortunately, no matching phases could be identified. This may indicate that the impurity peaks result from the presence of a hitherto uncharacterized phase. The identification of these secondary phases is subject of ongoing studies. We note that local spectroscopy measurements would be needed in order to obtain more precise information about the positions of atoms in the crystal structure.

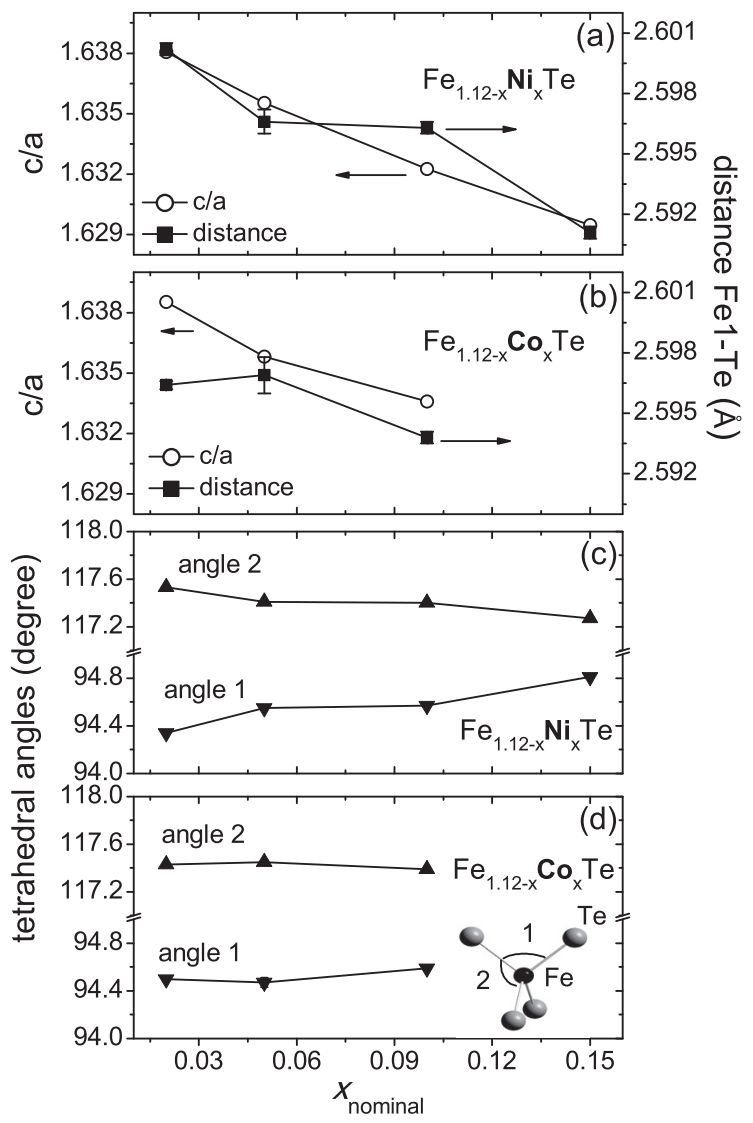

FIG. 11. The $c / a$ ratio and Fe-Te distance in the tetrahedron of (a) $\mathrm{Fe}_{1.12-x} \mathrm{Ni}_{x} \mathrm{Te}$ and (b) $\mathrm{Fe}_{1.12-x} \mathrm{Co}_{x} \mathrm{Te}$ at $100 \mathrm{~K}$. Tetrahedral angles of the Fe-Te tetrahedron at $100 \mathrm{~K}$ for (c) $\mathrm{Fe}_{1.12-x} \mathrm{Ni}_{x} \mathrm{Te}$ and (d) $\mathrm{Fe}_{1.12-x} \mathrm{Co}_{x} \mathrm{Te}$. In some cases, error bars are smaller than the symbol size. The basic building block of structure (Fe-Te tetrahedron) with the angles is drawn in (d).

In Figs. 11(a) and 11(b), the variation of the $c / a$ ratio and the Fe-Te distance in the tetrahedron [see Fig. 11(d)] with respect to increasing $\mathrm{Ni}$ and Co concentration at $100 \mathrm{~K}$ can be seen. Upon increasing the substitution level, the $c / a$ ratio of $\mathrm{Fe}_{1.12-x} M_{x} \mathrm{Te}$ samples decreases. For the same composition range, the $\mathrm{Fe}-\mathrm{Te}$ bond length in the tetrahedron is reduced by $0.10 \%$ for $\mathrm{Co}$ and $0.15 \%$ for Ni substitution. The composition dependence of the tetrahedral bond angles (Te-Fe-Te) of substituted samples is displayed in Figs. 11(c) and 11(d). The Te-Fe-Te angle (angle 1) along the $c$ direction increases, whereas the other Te-Fe-Te angle (angle 2) contracts upon increasing both $\mathrm{Ni}$ and $\mathrm{Co}$ concentration, which corresponds to a compression of the tetrahedron along the $c$ axis. Although the structural phase transition to the orthorhombic and monoclinic phases were suppressed by $\mathrm{Co}$ and $\mathrm{Ni}$ substitution in $\mathrm{Fe}_{1.12} \mathrm{Te}$, the changes of lattice parameters and atomic positions are insufficient to achieve the ideal tetrahedral bond angle which would favor superconductivity [41]. In accordance with this prediction, no superconductivity was observed down to $2 \mathrm{~K}$. 
TABLE III. Crystallographic data based on refinements using PXRD diagrams of $\mathrm{Fe}_{1.07} \mathrm{Co}_{0.05} \mathrm{Te}$ in the tetragonal phase at $100 \mathrm{~K}$ and in the mixed phase at $10 \mathrm{~K}$. Atomic displacement parameters $U_{\text {iso }}$ are given in $\left(10^{-2} \AA^{2}\right)$. Fe1 and Te are assumed as fully occupied and the occupancy parameters of these atoms are fixed to 1 .

\begin{tabular}{|c|c|c|c|}
\hline Temperature & $100 \mathrm{~K}$ & $10 \mathrm{~K}$ & $10 \mathrm{~K}$ \\
\hline Space group & $\mathrm{P} 4 / \mathrm{nmm}$ & $P 4 / n m m$ & Pmmn \\
\hline$a(\AA)$ & $3.81289(2)$ & $3.81019(2)$ & $3.81827(5)$ \\
\hline$b(\AA)$ & & & $3.80274(5)$ \\
\hline$c(\AA)$ & $6.23713(4)$ & $6.23317(3)$ & $6.2339(1)$ \\
\hline$\beta$ (deg.) & 90 & 90 & 90 \\
\hline$R_{I} / R_{P}$ & $0.014 / 0.098$ & $0.019 / 0.089$ & $0.021 / 0.089$ \\
\hline Number of reflections & 81 & 35 & 55 \\
\hline \multicolumn{4}{|l|}{ Refined parameters for } \\
\hline profile/crystal structure & $22 / 7$ & $27 / 7$ & $27 / 11$ \\
\hline \multicolumn{4}{|l|}{ Atomic parameters } \\
\hline \multirow[t]{2}{*}{$\mathrm{Fe} 1$} & $2 a\left(\frac{3}{4}, \frac{1}{4}, 0\right)$ & $2 a\left(\frac{3}{4}, \frac{1}{4}, 0\right)$ & $\begin{array}{l}2 b\left(\frac{3}{4}, \frac{1}{4}, z\right) \\
z=0.0042(6)\end{array}$ \\
\hline & $U_{\text {iso }}=0.40(2)$ & $U_{\text {iso }}=0.24(5)$ & $U_{\text {iso }}=0.11(4)$ \\
\hline \multirow[t]{4}{*}{$\mathrm{Fe} 2^{\mathrm{a}}$} & $2 c\left(\frac{1}{4}, \frac{1}{4}, z\right)$ & $2 c\left(\frac{1}{4}, \frac{1}{4}, z\right)$ & $2 a\left(\frac{1}{4}, \frac{1}{4}, z\right)$ \\
\hline & $z=0.723(6)$ & $z=0.710(3)$ & $z=0.707(5)$ \\
\hline & $U_{\text {iso }}=0.7(0)$ & $U_{\text {iso }}=0.4(0)$ & $U_{\text {iso }}=0.4(0)$ \\
\hline & $O c c .=0.07(1)$ & $O c c .=0.07(0)$ & $O c c .=0.07(0)$ \\
\hline \multirow[t]{4}{*}{$\mathrm{Co}^{\mathrm{a}}$} & $2 c\left(\frac{1}{4}, \frac{1}{4}, z\right)$ & $2 c\left(\frac{1}{4}, \frac{1}{4}, z\right)$ & $2 a\left(\frac{1}{4}, \frac{1}{4}, z\right)$ \\
\hline & $z=0.711(7)$ & $z=0.707(5)$ & $z=0.715(7)$ \\
\hline & $U_{\text {iso }}=0.7(0)$ & $U_{\text {iso }}=0.4(0)$ & $U_{\text {iso }}=0.4(0)$ \\
\hline & $O c c .=0.05(1)$ & $O c c .=0.05(0)$ & $O c c .=0.05(0)$ \\
\hline \multirow[t]{3}{*}{$\mathrm{Te}$} & $2 c\left(\frac{1}{4}, \frac{1}{4}, z\right)$ & $2 c\left(\frac{1}{4}, \frac{1}{4}, z\right)$ & $2 a\left(\frac{1}{4}, \frac{1}{4}, z\right)$ \\
\hline & $z=0.2827(1)$ & $z=0.2831(1)$ & $z=0.2835(2)$ \\
\hline & $U_{\text {iso }}=0.46(1)$ & $U_{\text {iso }}=0.29(3)$ & $U_{\text {iso }}=0.19(3)$ \\
\hline
\end{tabular}

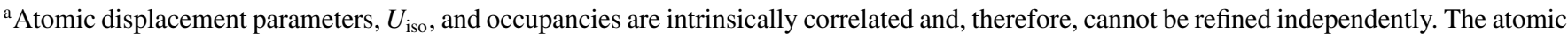
displacement parameters of the interstitial atoms are fixed at $U_{\text {iso }}=0.007 \AA^{2}$ at $100 \mathrm{~K}$ and $U_{\text {iso }}=0.004 \AA^{2}$ at $10 \mathrm{~K}$. The occupancies of interstitial atoms were refined separately without restricting their sum at $100 \mathrm{~K}$, and same occupancies were used in the refinement of the $10-\mathrm{K}$ data.

\section{CONCLUSIONS}

We investigated the effects of $\mathrm{Co}$ and $\mathrm{Ni}$ substitution in $\mathrm{Fe}_{1.12} \mathrm{Te}$ by conducting low-temperature synchrotron $\mathrm{x}$ ray diffraction experiments as well as thermodynamic and resistivity measurements on a series of samples. Our results demonstrate that the phase transitions are systematically shifted to lower temperatures and finally suppressed by these substitutions. The shifts are more pronounced for the $\mathrm{Ni}$ substitution suggesting that electron doping does not favor antiferromagnetism in these phases. Further, the spin-glasslike insulating behavior observed for substitutions $x \geqslant 0.05$ confirms localization induced by disorder [42] instead of metallic behavior expected from the electron doping. Although the magnetostructural phase transitions of $\mathrm{Fe}_{1.12} \mathrm{Te}$ could be suppressed by the partial replacement of excess Fe by Co or $\mathrm{Ni}$, superconductivity was not observed down to $2 \mathrm{~K}$ in the studied materials. Our data indicate that the structural changes appear to be by far insufficient to achieve the ideal value of the $\mathrm{FeTe}_{4}$ tetrahedral bond angle that would favor superconductivity.

\section{ACKNOWLEDGMENTS}

The authors thank G. Auffermann for chemical analysis and U. Burkhardt for EDX analysis. We acknowledge support by Andy Fitch and Yves Watier at beam-line ID22, ESRF Grenoble, during the experiments based on proposal No. HC1192. Stimulating discussions with Yu. Grin, and L. H. Tjeng are gratefully acknowledged. The project was supported by Deutsche Forschungsgemeinschaft, SPP 1458. AAT acknowledges the funding by the ESF (Mobilitas grant MTT77) and by the Estonian Research Council (PUT733).

\section{APPENDIX}

In the following tables, we compile the details of the structure refinements for $\mathrm{Fe}_{1.12-x} M_{x} \mathrm{Te}(x=0.02-0.15)$. 
TABLE IV. Crystallographic data based on refinements using PXRD diagrams of $\mathrm{Fe}_{1.10} \mathrm{Ni}_{0.02}$ Te in the tetragonal $(P 4 / \mathrm{nmm})$ phase at 100 $\mathrm{K}$ and in the orthorhombic $(P m m n)$ phase at $20 \mathrm{~K}$. Atomic displacement parameters $U_{\text {iso }}$ are given in $10^{-2} \AA^{2}$. Fe 1 and Te are assumed as fully occupied and the occupancy parameters of these atoms are fixed to 1.

\begin{tabular}{lll}
\hline \hline Temperature & $100 \mathrm{~K}$ & $20 \mathrm{~K}$ \\
\hline $\begin{array}{l}\text { Space group } \\
a(\AA)\end{array}$ & $P 4 / n m m$ & $P m m n$ \\
$b(\AA)$ & $3.81373(2)$ & $3.82752(3)$ \\
$c(\AA)$ & & $3.79499(2)$ \\
$R_{I} / R_{P}$ & $6.24712(4)$ & $6.24533(5)$ \\
Number of reflections & $0.023 / 0.087$ & $0.023 / 0.111$ \\
Refined parameters for & 49 & 80 \\
profile/crystal structure & & $23 / 7$ \\
Atomic parameters & $21 / 6$ & $2 b\left(\frac{3}{4}, \frac{1}{4}, z\right)$ \\
Fe1 & & $z=0.0021(2)$ \\
& $2 a\left(\frac{3}{4}, \frac{1}{4}, 0\right)$ & $U_{\text {iso }}=0.36(3)$ \\
Fe2 & & $2 a\left(\frac{1}{4}, \frac{1}{4}, z\right)$ \\
& $U_{\text {iso }}=0.58(3)$ & $z=0.718(2)$ \\
$\mathrm{Ni}^{\mathrm{a}}$ & $2 c\left(\frac{1}{4}, \frac{1}{4}, z\right)$ & $U_{\text {iso }}=0.4(0)$ \\
& $z=0.722(1)$ & $2 a\left(\frac{1}{4}, \frac{1}{4}, z\right)$ \\
$\mathrm{Te}$ & $U_{\text {iso }}=0.7(0)$ & $z=0.710(8)$ \\
& $2 c\left(\frac{1}{4}, \frac{1}{4}, z\right)$ & $U_{\text {iso }}=0.4(0)$ \\
& $z=0.717(6)$ & $2 a\left(\frac{1}{4}, \frac{1}{4}, z\right)$ \\
\hline \hline
\end{tabular}

$\overline{\bar{a}}$ The occupancies of interstitial atoms are fixed to their nominal compositions. The atomic displacement parameters of the interstitial atoms are fixed at $U_{\text {iso }}=0.007 \AA^{2}$ at $100 \mathrm{~K}$ and $U_{\text {iso }}=0.004 \AA^{2}$ at $20 \mathrm{~K}$.

TABLE V. Crystallographic data based on refinements using PXRD diagrams of $\mathrm{Fe}_{1.02} \mathrm{Ni}_{0.10} \mathrm{Te}$ in the tetragonal $(P 4 / \mathrm{nmm})$ phase at $100 \mathrm{~K}$ and $10 \mathrm{~K}$. Atomic displacement parameters $U_{\text {iso }}$ are given in $10^{-2} \AA^{2}$. Fel and Te are assumed as fully occupied and the occupancy parameters of these atoms are fixed to 1 .

\begin{tabular}{|c|c|c|}
\hline Temperature & $100 \mathrm{~K}$ & $10 \mathrm{~K}$ \\
\hline Space group & $P 4 / n m m$ & $P 4 / n m m$ \\
\hline$a(\AA)$ & $3.81504(1)$ & $3.81369(1)$ \\
\hline$c(\AA)$ & $6.22716(3)$ & $6.22118(3)$ \\
\hline$R_{I} / R_{P}$ & $0.052 / 0.131$ & $0.062 / 0.145$ \\
\hline Number of reflections & 49 & 49 \\
\hline \multicolumn{3}{|l|}{ Refined parameters for } \\
\hline profile/crystal structure & $21 / 5$ & $24 / 5$ \\
\hline \multicolumn{3}{|l|}{ Atomic parameters } \\
\hline \multirow[t]{2}{*}{$\mathrm{Fe} 1$} & $2 a\left(\frac{3}{4}, \frac{1}{4}, 0\right)$ & $2 a\left(\frac{3}{4}, \frac{1}{4}, 0\right)$ \\
\hline & $U_{\text {iso }}=0.50(0)$ & $U_{\mathrm{iso}}=0.5(0)$ \\
\hline \multirow[t]{3}{*}{$\mathrm{Fe} 2^{\mathrm{a}}$} & $2 c\left(\frac{1}{4}, \frac{1}{4}, z\right)$ & $2 c\left(\frac{1}{4}, \frac{1}{4}, z\right)$ \\
\hline & $z=0.733(9)$ & $z=0.749(8)$ \\
\hline & $U_{\text {iso }}=0.7(0)$ & $U_{\text {iso }}=0.4(0)$ \\
\hline \multirow[t]{3}{*}{$\mathrm{Ni}^{\mathrm{a}}$} & $2 c\left(\frac{1}{4}, \frac{1}{4}, z\right)$ & $2 c\left(\frac{1}{4}, \frac{1}{4}, z\right)$ \\
\hline & $z=0.699(2)$ & $z=0.703(1)$ \\
\hline & $U_{\text {iso }}=0.7(0)$ & $U_{\text {iso }}=0.4(0)$ \\
\hline \multirow[t]{3}{*}{$\mathrm{Te}$} & $2 c\left(\frac{1}{4}, \frac{1}{4}, z\right)$ & $2 c\left(\frac{1}{4}, \frac{1}{4}, z\right)$ \\
\hline & $z=0.2830(1)$ & $z=0.2833(1)$ \\
\hline & $U_{\text {iso }}=0.52(2)$ & $U_{\text {iso }}=0.47(2)$ \\
\hline
\end{tabular}

The occupancies of interstitial atoms are fixed to their nominal compositions. The atomic displacement parameters of the interstitial atoms are fixed at $U_{\text {iso }}=0.007 \AA^{2}$ at $100 \mathrm{~K}$ and $U_{\text {iso }}=0.004 \AA^{2}$ at $10 \mathrm{~K}$. 
TABLE VI. Crystallographic data based on refinements using PXRD diagrams of $\mathrm{Fe}_{0.97} \mathrm{Ni}_{0.15} \mathrm{Te}$ in the tetragonal $(P 4 / \mathrm{nmm})$ phase at 100 and $10 \mathrm{~K}$. Atomic displacement parameters $U_{\text {iso }}$ are given in $10^{-2} \AA^{2}$. Te is assumed as fully occupied and the occupancy parameter of this atom is fixed to 1 . The total occupancy parameter of Fe1 and Ni1 are fixed to 1 .

\begin{tabular}{lll}
\hline \hline Temperature & $100 \mathrm{~K}$ & $10 \mathrm{~K}$ \\
\hline$a(\AA)$ & $3.81470(1)$ & $3.81303(1)$ \\
$c(\AA)$ & $6.21598(2)$ & $6.20986(2)$ \\
$R_{I} / R_{P}$ & $0.049 / 0.124$ & $0.045 / 0.110$ \\
Number of reflections & 49 & 49 \\
Refined parameters for & & $21 / 5$ \\
profile/crystal structure & $21 / 5$ & $2 a\left(\frac{3}{4}, \frac{1}{4}, 0\right)$ \\
Atomic parameters & & $U_{\text {iso }}=0.65(2)$ \\
Fe1 & $2 a\left(\frac{3}{4}, \frac{1}{4}, 0\right)$ & $2 a\left(\frac{3}{4}, \frac{1}{4}, 0\right)$ \\
& $U_{\text {iso }}=0.76(1)$ & $U_{\text {iso }}=0.65(2)$ \\
Ni1 & $2 a\left(\frac{3}{4}, \frac{1}{4}, 0\right)$ & $2 c\left(\frac{1}{4}, \frac{1}{4}, z\right)$ \\
Ni2 $2^{\text {a }}$ & $U_{\text {iso }}=0.76(1)$ & $z=0.698(1)$ \\
& $2 c\left(\frac{1}{4}, \frac{1}{4}, z\right)$ & $U_{\text {iso }}=0.7(0)$ \\
Te & $z=0.701(1)$ & $2 c\left(\frac{1}{4}, \frac{1}{4}, z\right)$ \\
& $U_{\text {iso }}=0.7(0)$ & $z=0.2823(6)$ \\
& $2 c\left(\frac{1}{4}, \frac{1}{4}, z\right)$ & $U_{\text {iso }}=0.71(1)$ \\
\hline \hline
\end{tabular}

The occupancies of interstitial atoms are fixed to their nominal compositions. The atomic displacement parameters of the interstitial atoms are fixed at $U_{\text {iso }}=0.007 \AA^{2}$ at $100 \mathrm{~K}$ and $10 \mathrm{~K}$.

TABLE VII. Crystallographic data based on refinements using PXRD diagrams of $\mathrm{Fe}_{1.10} \mathrm{Co}_{0.02} \mathrm{Te}$ in the tetragonal $(P 4 / \mathrm{nmm})$ phase at $100 \mathrm{~K}$ and in the mixed phase at $10 \mathrm{~K}$. Atomic displacement parameters $U_{\text {iso }}$ are given in $10^{-2} \AA^{2}$. Fe 1 and Te are assumed as fully occupied and the occupancy parameters of these atoms are fixed to 1 .

\begin{tabular}{|c|c|c|c|}
\hline Temperature & $100 \mathrm{~K}$ & $10 \mathrm{~K}$ & $10 \mathrm{~K}$ \\
\hline Space group & $\mathrm{P} 4 / \mathrm{nmm}$ & $P 2_{1} / m$ & Pmmn \\
\hline$a(\AA)$ & $3.81322(1)$ & $3.83500(3)$ & $3.8327(1)$ \\
\hline$b(\AA)$ & $3.81322(1)$ & $3.78892(3)$ & $3.7899(1)$ \\
\hline$c(\AA)$ & $6.24802(2)$ & $6.24689(5)$ & $6.2472(2)$ \\
\hline$\beta$ (deg.) & 90 & $90.637(1)$ & 90 \\
\hline$R_{I} / R_{P}$ & $0.034 / 0.105$ & $0.036 / 0.155$ & $0.039 / 0.155$ \\
\hline Number of reflections & 49 & 136 & 79 \\
\hline $\begin{array}{l}\text { Atomic parameters } \\
\text { Fe1 }\end{array}$ & $2 a\left(\frac{3}{4}, \frac{1}{4}, 0\right)$ & $\begin{array}{c}2 e\left(x, \frac{1}{4}, z\right) \\
x=0.7400(4)\end{array}$ & $2 b\left(\frac{3}{4}, \frac{1}{4}, z\right)$ \\
\hline & $U_{\text {iso }}=0.40(2)$ & $\begin{array}{c}z=0.0036(3) \\
U_{\text {iso }}=0.2(0)\end{array}$ & $\begin{array}{l}z=0.003(1) \\
U_{\text {iso }}=0.2(0)\end{array}$ \\
\hline $\mathrm{Fe} 2^{\mathrm{a}}$ & $2 c\left(\frac{1}{4}, \frac{1}{4}, z\right)$ & $\begin{array}{c}2 e\left(x, \frac{1}{4}, z\right) \\
x=0.273(3)\end{array}$ & $2 a\left(\frac{1}{4}, \frac{1}{4}, z\right)$ \\
\hline & $z=0.731(1)$ & $z=0.710(2)$ & $z=0.728(6)$ \\
\hline & $U_{\text {iso }}=0.7(0)$ & $U_{\text {iso }}=0.4(0)$ & $U_{\text {iso }}=0.4(0)$ \\
\hline $\mathrm{Co}^{\mathrm{a}}$ & $2 c\left(\frac{1}{4}, \frac{1}{4}, z\right)$ & $\begin{array}{c}2 e\left(x, \frac{1}{4}, z\right) \\
x=0.273(3)\end{array}$ & $2 a\left(\frac{1}{4}, \frac{1}{4}, z\right)$ \\
\hline & $z=0.693(6)$ & $z=0.710(2)$ & $z=0.728(6)$ \\
\hline & $U_{\text {iso }}=0.7(0)$ & $U_{\text {iso }}=0.4(0)$ & $U_{\text {iso }}=0.4(0)$ \\
\hline $\mathrm{Te}$ & $2 c\left(\frac{1}{4}, \frac{1}{4}, z\right)$ & $\begin{array}{c}2 e\left(x, \frac{1}{4}, z\right) \\
x=0.2433(2)\end{array}$ & $2 a\left(\frac{1}{4}, \frac{1}{4}, z\right)$ \\
\hline & $z=0.2822(1)$ & $z=0.2830(1)$ & $z=0.2839(3)$ \\
\hline & $U_{\text {iso }}=0.36(1)$ & $U_{\text {iso }}=0.2(0)$ & $U_{\text {iso }}=0.2(0)$ \\
\hline
\end{tabular}

${ }^{a}$ The occupancies of interstitial atoms are fixed to their nominal compositions. The atomic displacement parameters of the interstitial atoms are fixed at $U_{\text {iso }}=0.007 \AA^{2}$ at $100 \mathrm{~K}$ and $U_{\text {iso }}=0.004 \AA^{2}$ at $10 \mathrm{~K}$. 
TABLE VIII. Crystallographic data based on refinements using PXRD diagrams of $\mathrm{Fe}_{1.02} \mathrm{Co}_{0.10}$ Te in the tetragonal $(P 4 / \mathrm{nmm})$ phase at 100 and $10 \mathrm{~K}$. Atomic displacement parameters $U_{\text {iso }}$ are given in $10^{-2} \AA^{2}$. Fel and Te are assumed as fully occupied and the occupancy parameters of these atoms are fixed to 1 .

\begin{tabular}{lcc}
\hline \hline Temperature & $100 \mathrm{~K}$ & $10 \mathrm{~K}$ \\
\hline Space group & $P 4 / n m m$ & $P 4 / n m m$ \\
$a(\AA)$ & $3.81229(1)$ & $3.81102(1)$ \\
$c(\AA)$ & $6.22770(3)$ & $6.22259(2)$ \\
$R_{I} / R_{P}$ & $0.017 / 0.082$ & $0.009 / 0.078$ \\
Number of reflections & 49 & 49 \\
Refined parameters for & & $21 / 6$ \\
profile/crystal structure & & $23 / 6$ \\
Atomic parameters & $2 a\left(\frac{3}{4}, \frac{1}{4}, 0\right)$ & $2 a\left(\frac{3}{4}, \frac{1}{4}, 0\right)$ \\
Fe1 & $U_{\text {iso }}=0.40(2)$ & $U_{\text {iso }}=0.28(3)$ \\
& $2 c\left(\frac{1}{4}, \frac{1}{4}, z\right)$ & $2 c\left(\frac{1}{4}, \frac{1}{4}, z\right)$ \\
Fe2 $2^{\mathrm{a}}$ & $z=0.726(7)$ & $z=0.721(6)$ \\
& $U_{\text {iso }}=0.7(0)$ & $U_{\text {iso }}=0.4(0)$ \\
Co & $2 c\left(\frac{1}{4}, \frac{1}{4}, z\right)$ & $2 c\left(\frac{1}{4}, \frac{1}{4}, z\right)$ \\
& $z=0.714(2)$ & $z=0.715(1)$ \\
Te & $U_{\text {iso }}=0.7(0)$ & $U_{\text {iso }}=0.4(0)$ \\
& $2 c\left(\frac{1}{4}, \frac{1}{4}, z\right)$ & $2 a\left(\frac{1}{4}, \frac{1}{4}, z\right)$ \\
& $z=0.2826(1)$ & $z=0.2826(1)$ \\
\hline \hline
\end{tabular}

${ }^{a}$ The occupancies of interstitial atoms are fixed to their nominal compositions. The atomic displacement parameters of the interstitial atoms are fixed at $U_{\text {iso }}=0.007 \AA^{2}$ at $100 \mathrm{~K}$ and $U_{\text {iso }}=0.004 \AA^{2}$ at $10 \mathrm{~K}$.

[1] T. M. McQueen, Q. Huang, V. Ksenofontov, C. Felser, Q. Xu, H. Zandbergen, Y. S. Hor, J. Allred, A. J. Williams, D. Qu, J. Checkelsky, N. P. Ong, and R. J. Cava, Phys. Rev. B 79, 014522 (2009).

[2] C. Koz, M. Schmidt, H. Borrmann, U. Burkhardt, S. Rößler, W. Carrillo-Cabrera, W. Schnelle, U. Schwarz, and Y. Grin, Z. Anorg. Allg. Chem. 640, 1600 (2014).

[3] C. Koz, S. Rößler, A. A. Tsirlin, S. Wirth, and U. Schwarz, Phys. Rev. B 88, 094509 (2013).

[4] W. Bao, Y. Qiu, Q. Huang, M. A. Green, P. Zajdel, M. R. Fitzsimmons, M. Zhernenkov, S. Chang, M. Fang, B. Qian, E. K. Vehstedt, J. Yang, H. M. Pham, L. Spinu, and Z. Q. Mao, Phys. Rev. Lett. 102, 247001 (2009).

[5] S. Li, C. de la Cruz, Q. Huang, Y. Chen, J. W. Lynn, J. Hu, Y.-L. Huang, F.-C. Hsu, K.-W. Yeh, M.-K. Wu, and P. Dai, Phys. Rev. B 79, 054503 (2009).

[6] E. E. Rodriguez, C. Stock, P. Zajdel, K. L. Krycka, C. F. Majkrzak, P. Zavalij, and M. A. Green, Phys. Rev. B 84, 064403 (2011).

[7] I. A. Zaliznyak, Z. J. Xu, J. S. Wen, J. M. Tranquada, G. D. Gu, V. Solovyov, V. N. Glazkov, A. I. Zheludev, V. O. Garlea, and M. B. Stone, Phys. Rev. B 85, 085105 (2012).

[8] S. Rößler, D. Cherian, W. Lorenz, M. Doerr, C. Koz, C. Curfs, Yu. Prots, U. K. Rößler, U. Schwarz, S. Elizabeth, and S. Wirth, Phys. Rev. B 84, 174506 (2011).

[9] Y. Mizuguchi, K. Hamada, K. Goto, H. Takatsu, H. Kadowaki, and O. Miura, Solid State Commun. 152, 1047 (2012).
[10] E. E. Rodriguez, D. A. Sokolov, C. Stock, M. A. Green, O. Sobolev, Jose A. Rodriguez-Rivera, H. Cao, and A. DaoudAladine, Phys. Rev. B 88, 165110 (2013).

[11] D. Cherian, S. Rößler, C. Koz, A. A. Tsirlin, U. Schwarz, S Wirth, and S. Elizabeth, J. Appl. Phys. 115, 123912 (2014).

[12] H. Okada, H. Takahashi, Y. Mizuguchi, Y. Takano, and H. Takahashi, J. Phys. Soc. Jpn. 78, 083709 (2009).

[13] C. Koz, S. Rößler, A. A. Tsirlin, D. Kasinathan, C. Börrnert, M. Hanfland, H. Rosner, S. Wirth, and U. Schwarz, Phys. Rev. B 86, 094505 (2012).

[14] J.-E. Jørgensen and D. Sheptyakov, Eur. Phys. J. B 86, 18 (2013).

[15] M. Bendele, A. Maisuradze, B. Roessli, S. N. Gvasaliya, E. Pomjakushina, S. Weyeneth, K. Conder, H. Keller, and R. Khasanov, Phys. Rev. B 87, 060409(R) (2013).

[16] T. J. Liu, J. Hu, B. Qian, D. Fobes, Z. Q. Mao, W. Bao, M. Reehuis, S. A. J. Kimber, K. Prokeš, S. Matas, D. N. Argyriou, A. Hiess, A. Rotaru, H. Pham, L. Spinu, Y. Qiu, V. Thampy, A. T. Savici, J. A. Rodriguez, and C. Broholm, Nat. Mater. 9, 718 (2010).

[17] A. Martinelli, A. Palenzona, M. Tropeano, C. Ferdeghini, M. Putti, M. R. Cimberle, T. D. Nguyen, M. Affronte, and C. Ritter, Phys. Rev. B 81, 094115 (2010).

[18] Y. Xia, D. Qian, L. Wray, D. Hsieh, G. F. Chen, J. L. Luo, N. L. Wang, and M. Z. Hasan, Phys. Rev. Lett. 103, 037002 (2009).

[19] R. Hu, E. S. Bozin, J. B. Warren, and C. Petrovic, Phys. Rev. B 80, 214514 (2009).

[20] L. Zhang, D. J. Singh, and M. H. Du, Phys. Rev. B 79, 012506 (2009). 
[21] X. Liu, C.-C. Lee, Z. J. Xu, J. S. Wen, G. Gu, W. Ku, J. M. Tranquada, and J. P. Hill, Phys. Rev. B 83, 184523 (2011).

[22] Z. Xu, J. Wen, G. Xu, Q. Jie, Z. Lin, Q. Li, S. Chi, D. K. Singh, G. Gu, and J. M. Tranquada, Phys. Rev. B 82, 104525 (2010).

[23] M. H. Fang, H. M. Pham, B. Qian, T. J. Liu, E. K. Vehstedt, Y. Liu, L. Spinu, and Z. Q. Mao, Phys. Rev. B 78, 224503 (2008).

[24] Hechang Lei, Rongwei Hu, E. S. Choi, J. B. Warren, and C. Petrovic, Phys. Rev. B 81, 094518 (2010).

[25] D. Cherian, S. Rößler, S. Wirth, and S. Elizabeth, J. Phys.: Condens. Matter 27, 205702 (2015).

[26] V. Petricek, M. Dusek, and L. Palatinus, JANA 2006. The Crystallographic Computing System, Institute of Physics, Praha, Czech Republic, www-xray.fzu.cz/jana.

[27] A. March, Z. Kristallogr. 81, 285 (1932).

[28] W. A. Dollase, J. Appl. Crystallogr. 19, 267 (1986).

[29] J. Janaki, T. G. Kumary, N. Thirumurugan, A. Mani, A. Das, G. V. N. Rao, and A. Bharathi, J. Supercond. Nov. Magn. 25, 209 (2012).

[30] Y. Mizuguchi, F. Tomioka, S. Tsuda, T. Yamaguchi, and Y. Takano, J. Phys. Soc. Jpn. 78, 074712 (2009).

[31] S. B. Zhang, H. C. Lei, X. D. Zhu, G. Li, B. S. Wang, L. J. Li, X. B. Zhu, W. H. Song, Z. R. Yang, and Y. P. Sun, Physica C 469, 1958 (2009).
[32] D. J. Gawryluk, J. Fink-Finowicki, A. Wiśniewski, R. Puźniak, V. Domukhovski, R. Diduszko, M. Kozłowski, and M. Berkowski, Supercond. Sci. Technol. 24, 065011 (2011).

[33] R. Shipra, H. Takeya, K. Hirata, and A. Sundaresan, Physica C 470, 528 (2010).

[34] A. Kumar, R. P. Tandon, and V. P. S. Awana, IEEE Trans. Magn. 48, 4239 (2012).

[35] R. D. Shannon, Acta Crystallogr. Sect. A 32, 751 (1976).

[36] H. Wang, C. Dong, Z. Li, J. Yang, Q. Mao, and M. Fang, Phys. Lett. A 376, 3645 (2012).

[37] I. A. Zaliznyak, Z. Xu, J. M. Tranquada, G. Gu, A. M. Tsvelik, and M. B. Stone, Phys. Rev. Lett. 107, 216403 (2011).

[38] A. M. Zhang, T. L. Xia, L. R. Kong, J. H. Xiao, and Q. M. Zhang, J. Phys.: Condens. Matter 22, 245701 (2010).

[39] Z. T. Zhang, Z. R. Yang, L. Li, C. J. Zhang, L. Pi, S. Tan, and Y. H. Zhang, J. Appl. Phys. 109, 07E113 (2011).

[40] G. Bergerhoff and I. D. Brown, in Crystallographic Databases, F. H. Allen et al. (Hrsg.) Chester, International Union of Crystallography (1987).

[41] D. C. Johnston, Adv. Phys. 59, 803 (2010).

[42] S. Rößler, D. Cherian, S. Harikrishnan, H. L. Bhat, S. Elizabeth, J. A. Mydosh, L. H. Tjeng, F. Steglich, and S. Wirth, Phys. Rev. B 82, 144523 (2010). 